\title{
Interim Prosthesis for Repositioning of Mandible in a Hemimandibulectomy Patient: A Case Report
}

\author{
Mandeep Kaur, Sakshi M Kaura, Amit Sharma, and Simarpreet Kaur
}

\section{ABSTRACT}

\begin{abstract}
Background: Squamous cell carcinoma is prevalent in middle asia due to prevalence of tobacco chewing. Management includes removal of mandibular bone along with adjacent muscles and nerves. Mandible is attached to cranium with the support of muscles. Removal of muscles results in deviation of mandible and loss of occlusion, which is necessary for functions such as chewing, swallowing and to some extent in speech. Prosthetic appliances help in restoration of position of mandible and thus restoring the function.
\end{abstract}

Case Report: This is a case of 58 year old male with hemimandibulectomy due to moderately differentiated squamous cell carcinoma.

Treatment Plan: Interim guiding prosthesis was planned for mandibular repositioning as the patient did not report before the surgical excision.

Conclusion: a definitive management would be undertaken by using cast partial dentures after mandibular repositioning with interim prosthesis is done.

Keywords: guided flange appliance, hemi-mandibulectomy, squamous cell carcinoma.
Submitted : April 03, 2021

Published : April 24, 2021

ISSN: $2593-8339$

DOI: $10.24018 /$ ejmed.2021.3.2.801

Dr. Mandeep Kaur*

Apex Dental Care, Patiala, India.

(e-mail: dr.mandeepkaur@ymail.com)

Dr. Sakshi M Kaura

Department of Prosthodontics, Luxmi Bai Institute of Health and Dental Sciences, Patiala, India.

(e-mail: sakshikaura ${ }^{\circledR}$ gmail.com)

Dr. Amit Sharma

Department of Prosthodontics, Luxmi Bai Institute of Health and Dental Sciences, Patiala, India.

(e-mail: amit_sharma2035@yahoo.com)

Dr. Simarpreet Kaur

Department of Prosthodontics, Luxmi Bai Institute of Health and Dental Sciences, Patiala, India.

(e-mail: simarmehra7869@gmail.com)

*Corresponding Author

\section{INTRODUCTION}

The prosthodontic rehabilitation of patients with mandibular defects is challenging. The unilateral loss of mandibular continuity due to surgery or trauma results in mandibular deviation toward the defect side with lack of occlusion. Unlike the dentulous patients, edentulous patients face difficulty to retrain mandibular movements and many times may never achieve maxillomandibular relationships for optimum mastication and appearance [1].

Deviation of the mandible to the affected side is due to absence of muscles and nerves which help in positioning of the mandible, as mandible does not have any fixed bony attachment to the skull except for the articulation of mandibular condyle with temporal bone. The normal position and movement of the mandible is maintained by muscular attachments. Surgical excision of carcinoma involves removal of a large bundles of corresponding muscle mass along with bone. They may or may not preserve the marginal bone depending upon the extent of involvement of lesion [2].

Numerous classifications of defects have been proposed. New classification system based on the four corners of the mandible includes [3]:

Class I (angle): Lateral defect not including ipsilateral canine or condyle.

Class Ic (angle and condyle): Lateral defect including condyle.

Class II (angle and canine): Hemi mandibulectomy including ipsilateral but notcontralateral canine or condyle.

Class IIc (angle, canine, and condyle): Hemi mandibulectomy including condyle.

Class III (both canines): Anterior mandibulectomy includes both canines but neither angle.

Class IV (both canines and at least one angle): Extensive anterior mandibulectomy including both canines and one or both angles.

Class IVc (both canines and at least one condyle): Extensive anterior mandibulectomy including both canines and one or both condyles.

This case report presents the management of a patient with discontinuity resection with interim prosthesis for repositioning of the mandible before undergoing any final prosthetic rehabilitation. 


\section{CASE REPORT}

A 58-year-old male patient reported in the Department of Prosthodontics, with the complaint of having difficulty in chewing and speech due to loss of teeth. Patient gave history of pain and swelling on lower right side of the jaw about a year ago. Medical reports revealed resection of right mandible without disarticulation, right radical neck dissection and reconstruction with pectoralis major myocutaneous flap for management of moderately differentiated squamous cell carcinoma. Further history revealed the habit of tobacco chewing for 30 years. Extraoral examination indicated facial asymmetry (Fig. 1).

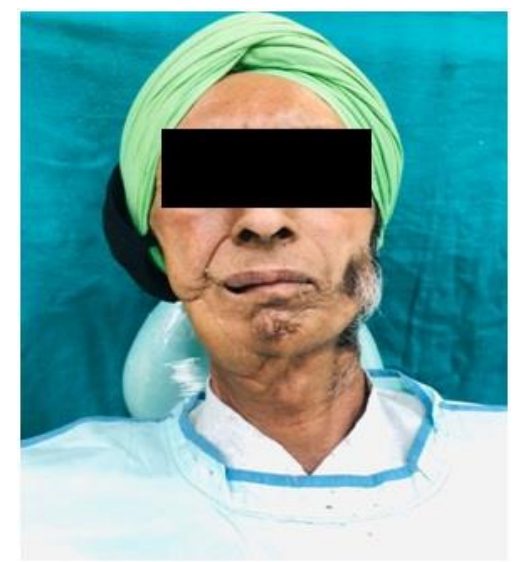

Fig. 1. Extra-oral view

Intra-oral examination revealed presence of surgically closed wound which showed consolidated cicatricial tissues in area of mandibular resection and generalized attrition in remaining dentition and Grade III mobile 31 and 36 (Fig. 2).

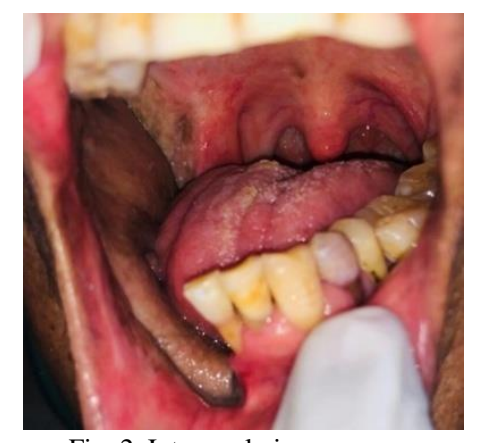

Fig. 2. Intra-oral view.

On radiological examination (Fig. 3), the remaining dentition was found to be periodontically compromised, but the ongoing chemotherapy limited the option of either extraction of teeth or surgically rehabilitation with implants or jaw reconstruction surgery.

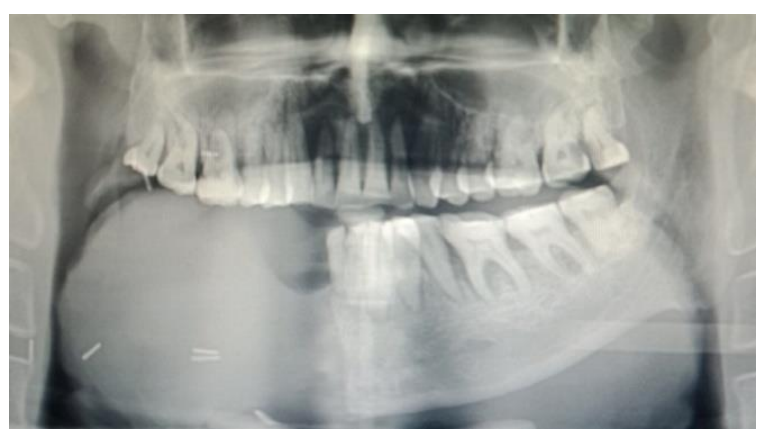

Fig. 3. Orthopantomogram
First step in prosthetic rehabilitation of the patient included mandibular repositioning. Interim prosthetic appliance was suggested for this along with some physiotherapy exercises until any definitive procedure could be performed.

Impressions were made with irreversible hydrocolloid for the maxillary arch and polyvinyl siloxane for the mandibular arch (Fig. 4).

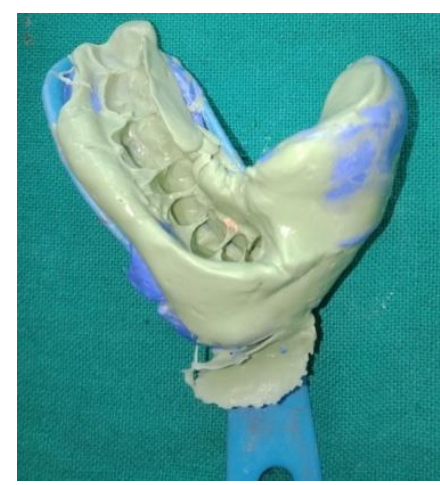

Fig. 4. Mandibular impression.

Maxillary cast was poured in type III dental stone and mandibular in Type IV die stone (Fig. 5).

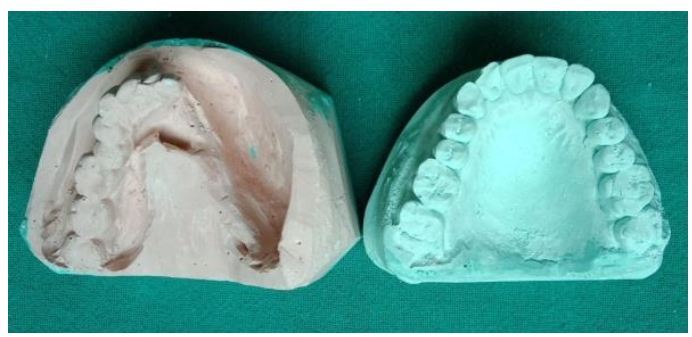

Fig. 5. Master casts.

Self-cure acrylic resin denture base with wax occlusal rims were constructed on the lower cast and then maxillamandibular relationship recorded by positioning the mandible manually in centric relation position. The mounting of the casts was done on mean value articulator and semi anatomic teeth were place. During try-in, it was noticed that patient could not hold the mandible in one position even after using mandibular guidance appliance in maxilla. So, to give freedom in centric till any definitive procedure can be performed, the teeth were removed. Twin occlusion was not given as there were more than 2 positions for occlusion. Patient was explained about limitations and he agreed to the treatment plan.

The prosthesis was cured with heat cured acrylic using the conventional technique and then it was trimmed and finished. On the prosthesis insertion appointment, some tooth colored chemical cured acrylic was placed over the occlusal surface after trimming some acrylic. This was inserted in patient's oral cavity and patient was asked to close mouth numerous times, so that the maxillary teeth indentations would give the desired occlusal surface for stability.

For retention purpose, a 22-gauge orthodontic wire was used for maxillary prosthesis that followed the contour of buccal teeth surfaces below the height of contour and two pin heads were given on distal side on both the canines (Fig. 6). 


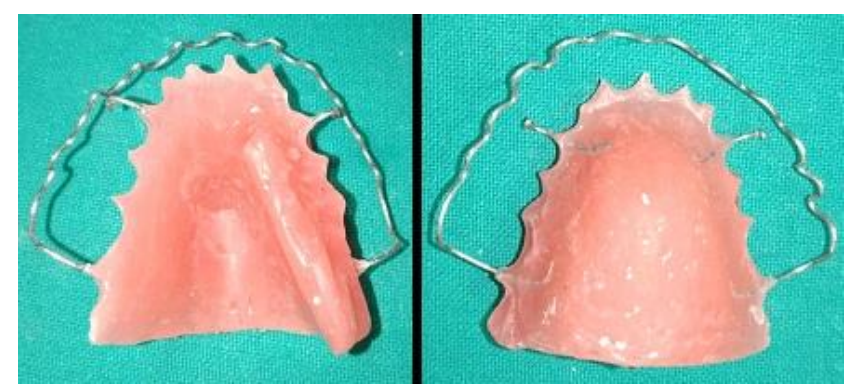

Fig. 6. Maxillary prosthesis.

The mandibular prosthesis was retained by making buccal flange of the prosthesis and an additional retentive feature of orthodontic band on mandibular left second molar was used.

Patient was trained for insertion and removal of prosthesis and was given instructions for the maintenance of the prosthesis (Fig. 7).

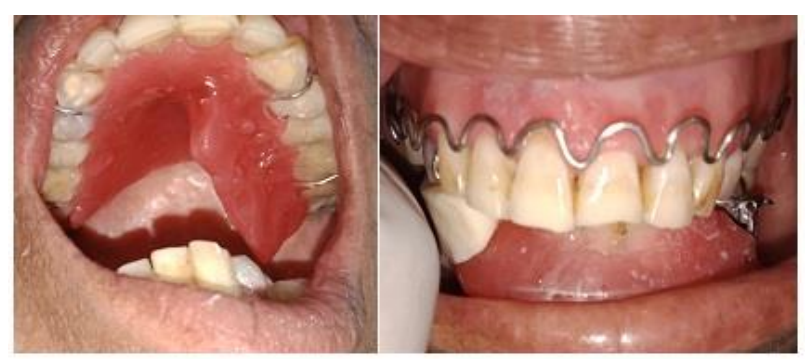

Fig. 7. Final prosthesis post-insertion.

Three-month follow up showed improvement in mandibular positioning. Final prosthesis will be fabricated after consent from the physician and completion of chemotherapy.

\section{DISCUSSION}

Mandible has a considerable impact on the quality of life as it important in esthetics as well as various functions such as speech, deglutition, mastication etc. Extent of oral cancer can vary from involving the superficial gingival tissue to invading the nerves and perineural tissue via marrow spaces. Management of squamous cell carcinoma depends on the stage of the cancer, extent of the tissues involved and the time of patient reporting for prosthetic rehabilitation [4]. In the present case, the cancer was classified as moderately differentiated squamous cell carcinoma. Since, the tissue involvement was extensive, so the treatment included resection of the right side of the mandible followed by radiotherapy. The patient did not visit any dental clinician for post-operative rehabilitation, pre-operatively.

Mandible is a floating bone held in position by muscles. Resection of the mandible along with muscles affects its position and stability. Radiotherapy affects the mucosa, salivary glands and bone. Any surgical reconstruction or extraction of the tooth may lead to osteoradionecrosis and failure of the reconstruction [5]. In the present case, reconstruction was not followed immediately after the surgery. Since the patient did not report before commencement of the surgery for resection of mandible, periodontically compromised teeth were not removed and they challenged the rehabilitation process.
Training appliances are made and given to patient if the patient reports before surgery as they help in keeping the mandible in position and minimizing the loss of esthetics and occlusion on unaffected side [6]. Since the patient reported after start of radiotherapy, the rehabilitation became more challenging as there was loss of occlusion and function. Trismus was also observed which limited impression making [7].

Lack of bony base further compromised the treatment options. Implants could not be given. Remaining dentition included some periodontally compromised teeth which further restricted the amount of force which can be borne by the remaining dentition [8].

Aim of the rehabilitation now was to prevent further damage to the oral structures and reverse the effects of hemi mandibulectomy which had already occurred. First objective was to establish the ideal occlusion and reduce trismus [9]. For this, physiotherapy and several exercises were recommended which would strengthen the remaining muscles and aid in rehabilitation. For re-establishing the occlusion, mandibular guide prosthesis was planned [10]. Since, this was an interim prosthesis, it was planned in acrylic resin which could be adjusted easily when required as forceful manual manipulation also did not help in reestablishing occlusion [11]. A vertical block of acrylic placed on the palatal side with indentations of the mandibular teeth would keep them in position. This acrylic appliance was supported by a crib of wire placed on buccal surface [12].

Trismus limited the mandibular impression making of whole of the defect [13]. Labial acrylic support was given as lingual would have interfered with guiding appliance placed in maxilla. The orthodontic band was used for retention as no other undercut could be utilized because of the periodontal condition of the abutment tooth.

Placing the mandibular guidance appliance did not help in stabilizing the occlusion. There were more than two positions for occlusion which contra-indicated the use of even twin occlusion. So, tooth colored acrylic was placed over the mandibular rim which would act as an interim appliance.

\section{CONCLUSION:}

Pre-surgical consultation with the prosthodontist is utmost important in the rehabilitation of carcinoma patient. The absence of any post -surgical appliance can present with many difficulties, as in present case, of unstable positioning of the mandible and absence of any occlusion. The present article describes the fabrication of training interim prosthesis for the repositioning of the deviated mandible towards the hemi-mandibulectomy site. Maxillary guide plane was used to reposition the mandible to the most accepted position and mandibular interim prosthesis was fabricated to train the patient in functional movements like swallowing and chewing to some extent.

The positive mental attitude of the patient towards the treatment led to overcoming the limitations of prosthetic rehabilitation, giving a satisfactory result. The patient was satisfied with the outcome of the interim prosthesis. 


\section{REFERENCES}

[1] Schneider RL, Taylor TD, "Mandibular resection guidance prostheses: A literature review", J Prosthet Dent.; vol 55, pp. 84-86, Jan1986.

[2] Cantor R, Curtis TA, "Prosthetic management of edentulous mandibulectomy patients. I. Anatomic, physiologic, and psychologic considerations", J Prosthet Dent, vol 25, pp. 446-457, April 1971.

[3] James S Brown, Conor Barry, Michael Ho, Richard Shaw, "Classification for mandibular defects", Lancet Oncol, vol 17, pp. 23 30, Jan 2016

[4] KSTHNS et al. "Guidelines for Surgical Management of Oral Cancer", Clinical and Experimental Otorhinolaryngology Vol. 12, No. 2: pp. 107-144, May 2019.

[5] Curtis TA, Taylor RC, Rositano SA, "Physical problems in obtaining records of the maxillofacial patient", J Prosthet Dent., vol 34, pp. 539 554, Nov 1975.

[6] Sahin N, Hekimoglu C, Aslan Y. "The fabrication of cast metal guidance flange prostheses for a patient with segmental mandibulectomy: A clinical report", J Prosthet Dent., vol 93, pp. 217 220, March 2005.

[7] Firtell DN, Curtis TA. "Removable partial denture design for the mandibular resection patient", $J$ Prosthet Dent. 1982; vol 48, pp. $437-$ 443, October 1982

[8] Beumer J 3rd, Curtis TA, Marunick MT. Ishiyaku Euro America; 1996. Maxillofacial Rehabilitation: Prosthodontic and Surgical Consideration; International Journal of Dental Sciences and Research 2014, Vol. 2 No. 6, 184-188.

[9] Desjardins RP. "Occlusal considerations for the partial mandibulectomy patient", J Prosthet Dent., vol 41, pp. 308-315, March 1979.

[10] Robinson JE, Rubright WC. "Use of a guide plane for maintaining the residual fragment in partial or hemi mandibulectomy", $J$ Prosthet Dent., vol 14, pp. 992-999, September 1964.

[11] Curtis TA, Cantor R. "The forgotten patient in maxillofacial prosthetics", J Prosthet Dent., vol 31, pp. 662-680, June 1974.

[12] Prakash V. "Prosthetic rehabilitation of edentulous mandibulectomy patient: A clinical report", Indian J Dent Res., vol 19, pp. 257-260, 2008.

[13] Swoope CC. "Prosthetic management of resected edentulous mandibles", J Prosthet Dent., vol 21, pp. 197-202, February 1969.

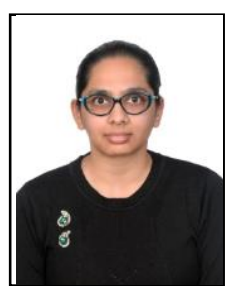

\section{Mandeep Kaur}

Born in Punjab 1989, Dr. Mandeep Kaur graduated from Baba Farid University of Health Sciences in 2012 and did Masters in Prosthodontics and Crown \& Bridge from the Baba Farid University of Health Sciences in 2017.

She worked as a Senior Lecturer in department of Prosthodontics and Crown \& Bridge in Baba Farid University of Health Sciences for 2 years. She is working as a Prosthodontist at Apex Dental Care since 2017. Among the publications:

1. Kaur M, Kumar S, Kaura SM, Kaur S, Singh J, Fabrication of flangeless complete denture to improve esthetics: a case report, international journal of clinical and diagnostic research, 2018;6,2,1-8.

2. Kaur, M., Kaura, S., Sharma, A., \& Showkat, R. (2020). Restoration of Microtia by Prosthetic Method: A Case Report. European Journal of Medical and Health Science, 2(4).

3. Kaur M, Kaura SM, Kumar S, Mahajan A. A Winged Denture for the Management of Flabby Prominent Premaxilla in Class III Ridge Relation: A Case Report. J Adv Med Dent Scie Res 2020;8(7):67-71. 